\title{
Multidisciplinary Model of Palliative Care Team
}

\author{
${ }^{1}$ Dagestan state University, Makhachkala, Russia \\ ${ }^{2}$ Dagestan state medical University, Makhachkala, Russia \\ ${ }^{3}$ Chechen state University, Grozny, Russia \\ *Corresponding author. Email: angelasagidova@mail.ru
}

Damadaeva A.S. ${ }^{1, *}$ Mollaeva N.R. ${ }^{2}$ Behoeva A.A. ${ }^{3}$

\begin{abstract}
The article analyzes the conditions and factors aimed at effective medical and social assistance (hereinafter SMA) for people who, due to their illness, disability or old age should improve their quality of life. A model of a multidisciplinary palliative care team is presented, which should ensure the organization of such palliative care. The development of palliative care should provide for various organizational forms of its provision, depending on the needs of the population and the characteristics of the region, but they can be divided into two main groups, i.e. care in inpatient institutions and care at home. However, it should be borne in mind that the main goal of home care for palliative patients is not only in the purely medical plane, but even more so in the social plane. After all, patients, especially those with non-oncological nosology, need not only pain relief at home, but also comprehensive care, medical, psychological and spiritual support. The problem is very urgent, but unfortunately, there is no clear system and normative documents regarding this issue. The article analyzes the problems of organization and research as well as methodological support for the provision of medical and social assistance to the population. Particular attention is paid to the possibilities for provision of medical and social assistance to incurable patients. In connection with the urgency of the problem, as well as with the problem of its organization, this article provides an analysis of the principles of giving palliative care. To achieve the objectives of the study, a model of such assistance provision in other countries and its comparison with the existing model in Russia and, in particular, in the Republic of Dagestan is considered. As a result of the given data, an MPCT model and its step-by-step solution are proposed.
\end{abstract}

\section{Keywords: social maladjustment, health care, psychocorrectional work, palliative, social work}

\section{INTRODUCTION}

In the international documents as well as in foreign practice starting the second half of the twentieth century special attention has been paid to ensuring human rights to medical and social assistance, provision in case help is needed, etc. and the like. The relevance of SMAs at the beginning of the twentieth century in Russia and another countries is associated with a number of demographic factors, namely, a significant increase in the number of people in older age groups and a degradation in the life quality in general. Researchers understand medical and social assistance as the interdisciplinary activity of physicians, psychologists, teachers, and social workers $[1,3]$. It fundamentally changes the comprehensive care in the health sector, as it provides for systemic medical and social interventions at the early stages of development of the disease and social maladjustment, which potentially lead to severe complications or disability. Thus, medical and social assistance has not only a pronounced rehabilitation, but also a preventive focus [4].

A feature of medical and social assistance is manifested in the fact that it is interdisciplinary and the participants in this process are both health care structures and social and psychological support of the process. In practice, health workers often act as social workers. In turn, social workers and psychologists work with persons with mental and physical pathologies and act as doctors.

Thus, medical and social assistance is closely intertwined with the activities of institutions of the health care system and social protection of the population, but it is qualitatively different, since it does not provide for diagnostic procedures and treatment.

Medical and social assistance acquires particular relevance when working with terminally ill patients. Social workers provide patronage of families and meet their needs, provide constant information about the patient's health, provide assistance in obtaining material assistance, etc. Social workers help to resolve conflict situations, represent the interests of the client in the authorities. If necessary, they carry out psychocorrectional work with the client and his immediate environment, conduct trainings to restore family relationships. Family members are involved in self-assistance and mutual- assistance groups.

At the same time, assistance can be provided to the disabled persons undergoing rehabilitation, support for persons' prone to suicidal behavior, expert assessments and expertise, psychological support for family members. Besides, social workers develop individual rehabilitation programs $[5,6]$. 
Study objective. The purpose of this study is to build a model of palliative care based on an analysis of the situation in Russia and in particular in the Republic of Dagestan.

\section{METHODS AND MATERIALS}

On 11 December 2019, the Republic of Dagestan approved the state program for the development of the palliative care system (hereinafter PC). In both Dagestan and the Russian Federation, the profound demographic changes are taking place, which consist in the aging of the population with a significant accumulation of elderly and senile people in the population. The progressive aging of the population, a significant change in the structure of diseases towards chronic pathology leads to an increase in the number of patients with severe chronic diseases who lose the ability to self-care and as a result they need outside help.

The latest WHO recommendations are the refocusing of the modern systems for palliative care provision for people with incurable diseases to out-of-hospital services that are not only equal to traditional inpatient treatment, but are also cost-effective. In addition, from the point of view of social significance, comprehensive home care dominates without any alternative, since it is a more complex SMA, which is necessary for palliative patients [8].

The experience of countries with a high level of development of palliative care indicates that this form of organization is a priority. The need to organize a PC system at home has several reasons, namely: the traditional family structure has changed, most people, especially the elderly, live separately and cannot count on family support; the number of existing inpatient specialized medical and social institutions with appropriate conditions is insufficient to meet the needs for inpatient treatment of all palliative patients [9]. In addition, $75.0 \%$ of people with progressive forms of chronic diseases and their relatives wish to have such help at home. At the same time, the services of palliative medicine (pain relief) are mainly in need of cancer patients, who make up no more than $10.0 \%$ of all those who need specialized care. Patients of other nosologies are in need of comprehensive care as well as medical, psychological, social and spiritual support [10].

Palliative patients are in between the area of activity of health authorities and social protection authorities and, in fact, are left without guaranteed specific care. If the medical component of the PC, including the reduction of pain syndrome, is partially solved, although there are still many problems here, the direction regarding social component in the country is only becoming a subject of the study [11].

The development of care for seriously ill (incurable) patients and their family members cannot be considered without taking into account the development of the health care system as a whole.

\section{RESULTS}

A study of the regulatory documents released on the website showed that in 2020, the authorities of Dagestan opened two palliative care departments for children and adults on the basis of the City Clinical Hospital No. 1 and at the Children's Clinical Hospital No. 1. It is planned to open four outpatient oncological care centers. They are planned to open in the cities of Makhachkala, Kizlyar and Izberbash on the basis of the Republican Cancer Center. Schools for palliative patients are also planned to be established, where they will be provided with psychological assistance. At the same time, there are problems regarding the implementation of such assistance, i.e. the lack of hospitals and hospices to provide assistance to the terminally ill people.

In this regard, some organizational points that have received little attention until now and which, being the characteristic of the health care system as a whole, have a significant impact on the provision of palliative care to patients and their families who are faced with the problem of a serious, incurable disease will be highlighted:

- The scale of the problem and the lack of attention of supervising structures to those in need of palliative care.

- The lack of a clear policy on the provision of PC both in relation to the categories of patients and in relation to the diseases they often suffer from.

- The problem of the regulatory and legal support as well as financing sources for the network of institutions for the provision of $\mathrm{PC}$ at home remains open.

- The issue of the integration and coordination between the services of medical care and social protection, state and non-state organizations has not been sufficiently worked out.

- The system of informing the public on the problems of PC is imperfect, which hinders the infusion of material and other types of assistance from the business structures, non-governmental and charitable organizations.

In addition, it is necessary to take into account the negative aspects of the professional activities of the staff serving seriously ill patients - high stress levels, significant emotional and physical stress, constant contact with the process of dying and death, the lack of positive results of the efforts made, an increased risk of developing burnout syndrome, etc. ... According to the international and domestic experts, these factors can be the reason for the high turnover of medical personnel inherent in the field of PC in everything due to the lack of prestige [12].

It is not a rare case when the issue of specialist training in the field of PC has not been resolved. There is no 
training in the field of palliative care. An explanatory conversation with patients is not carried out [2].

Thus, all the information provided is evidence of the inadequacy of the existing system for providing patients with affordable SMEs at home, which should be based on the following basic principles:

- The availability at all stages and levels of the treatment process. Access to the PC service depends on the clinical indicators of the disease. It is determined on the basis of an assessment of the probable prognosis of its development, does not depend on the economic status and financial condition of the patient, and is guaranteed in accordance with his or her needs.

- The provision of qualified PC for all patients in need.

- The provision of palliative patient with the opportunity to choose the place and options for receiving $\mathrm{PC}$.

- The integrity of PC consisting of medical and social as well as psychological activities; support provision to patients and members of his family (guardians).

- The integration of home health care services into the existing regional health and social protection systems.

These principles should be applied in the early stages of a chronic illness.

Detecting a disease at an early stage that does not give the patient any prospects for recovery, but the life is not limited. In this case the provision of medical and social services should be provided by a non-specialized service from among those who directly care for the patient (most often these are family members or other persons guardians), local medical personnel of general practice, social worker, volunteer and so on. All of them have no special training in the provision of PC.

The organizational form of $\mathrm{PC}$ at home can be special field services, which are either an independent structure or a subdivision of a stationary institution. The definition of specific organizational forms depends on the needs of the population in $\mathrm{PC}$, the size and characteristics of the region, the actual provision of it with specialized bedding.

The main mechanism for providing $\mathrm{PC}$ at home should, in our opinion, be a multidisciplinary team of PC (hereinafter - MPCT).

The MPCT model makes it possible to provide the patient with comprehensive and not purely medical or social support. The minimum composition of the MPCT is social and medical professionals, psychologist, social worker, and volunteers. This team includes family members of patients if they have acquired the skills to care for palliative patients.
The composition of the team is not stable. It depends on the specific situation, the needs of patients, and the available opportunities. The PC provided to sick children, which is mainly provided at home requires a pediatrician in the team.

In the MPCT, the medical aspect is based on pain relief. Next comes care, which constitutes the prerequisites for bodily comfort (as far as possible). The most difficult are psychological problems, since they affect both the inner world of patients and their relationship with the environment, interests, etc.

For palliative patients, it is vital, in addition to social services, to obtain legal assistance. The support for patient family members should begin with the diagnosis of a chronic illness, with an initial assessment of the situation, and continue throughout the PC period. An important step is bereavement support.

The solution of the above problems and tasks for the provision of PC should be achieved by implementing the following steps:

- to analyze the needs and provision of the population with PC services at home. This will determine the needs for the relevant PC services, personnel of different levels and qualifications, and will identify obstacles (social, economic, legal, etc.) to the population's access to PC;

- to develop regulatory framework on PC issues for various categories of patients, including those served at home. It is based on the main provisions of generally accepted international documents of the corresponding direction in the field of health care and social services;

- to ensure the rights of palliative patients by making appropriate changes to the current legislation regulating the circulation of opioid analgesics (with an emphasis on patients served at home) and developing a special law that will regulate legal relations in the provision of $\mathrm{PC}$, establish responsibility for violation of the rights of terminally ill patients;

- to define clear medical, legal and social criteria for PC provision at home;

- to develop the PC quality standards and their dissemination among all institutions specializing in the provision of PC to the patients, including those who are at home. The standards are developed at the federal and regional levels. At the federal level standards are created in order to develop a strategy for the development of software and control (monitoring) and at the regional level they are developed with the aim to adapt federal standards to the specific features of a region or a particular institution; 
- to develop and approve a standard regulation on the department of home-based PC at the territorial center of social services (provision of social services), job description for specialists and employees of this department;

- to give official definition of a special subject of $\mathrm{PC}$ with the assignment of the status of palliative patient;

- to determine special types of social services for persons who have received the status of palliative patients;

- $\quad$ to develop unified register of palliative patients with the definition of all forms of $\mathrm{PC}$ provision (at home, in a hospice, in specialized departments of inpatient medical institutions, etc.) and specialized software;

- to provide support (psychological, social, legal, etc.) to relatives and guardians who provide constant care for palliative patients at home. It is necessary to resolve the issue of granting them the right to the palliative patient care leave at the legislative level, as well as to open institutions for the weekend care provision, etc.;

- to develop a procedure for the interaction and delineation of functions of services involved in working with palliative patients in all forms of its provision;

- to separate specialist training in PC. This will help to obtain statistical data on the number of patients with various forms of chronic diseases who are provided with PC at home or in inpatient medical institutions, to determine the objective need for relevant specialists and their training;

- to select qualified personnel for the implementation of PC from the experienced specialists and organize constant training under professional development programs;

- to train specialists for servicing palliative patients within three levels: basic - training of all medical and social workers; medium - professional development of medical and social workers of various specialties on PC issues; higher - on the basis of higher educational institutions of postgraduate education to obtain specialization in palliative care;

- to gain state support for charity and develop the culture of patronage among wealthy the population;
- $\quad$ to support and develop civil society organizations that seek to develop PC, participate in the development of a regulatory framework, and contribute to the training of qualified personnel. To coordinate their activities jointly with the public sector;

- $\quad$ to get support from private structures, volunteers who focus their efforts on providing medical, social, legal assistance, moral and spiritual support to palliative patients and their families;

- to determine the admission mechanism for free of charge education in medical and social higher educational institutions for persons who worked as volunteers with the palliative patients;

- to raise the level of awareness of the population on PC issues about the possibilities of obtaining a wide range of medical, social, legal and psychological services at home in case of an incurable disease.

\section{CONCLUSION}

Currently, the problem of medical provision of patients with incurable diseases with severe clinical consequences is moving from the category of purely medical to a global social and humanitarian problem, the successful solution of which depends on the mobilization and unification of the efforts of the state and public institutions to attract all necessary resources and create an appropriate medical infrastructure in order to meet the needs of PC patients in the terminal phase of life.

In difficult conditions of limited financial and material resources, the issue of establishing closer interaction between the state institutions of all levels, business structures and public organizations is one of the key direction in improving the provision of PC.

An embodiment of such a public project should be the formation of charitable foundations and funds for social support of patients with incurable diseases, the development of volunteer movement within the framework of the national policy with appropriate training of its participants to provide social assistance to such patients in their daily life.

A significant role in this regard can be played by the development and implementation of a nationwide comprehensive targeted program of medical and social protection of patients in the terminal phase of life, as a real manifestation of social and humanitarian policy in today's conditions and the long-term development of society on qualitatively new principles of social standards.

Thus, the issue of consolidating the efforts of the state and the public sector should be considered as an important vector for the development of the PC system, which requires the approval of a long-term program at the national level and the improvement of the corresponding 
regulatory framework to create real prerequisites for improving the medical and social protection of patients with incurable diseases.

\section{REFERENCES}

[1] N.R. Mollaeva, A.S. Damadaeva, Topical issues and development base for palliative care for the population, in Collection: Modern paths of development of the social sphere: education, experience, problems, science, trends, prospects, 2017, pp. 136-137.

[2] S.A. Magomedov, N.T. Magdieva, S.D. Musaeva, A.S. Damadaeva, D.M. Mameeva, Opportunities of Social Medicine Department as an educational and methodological center for training specialists in the field of medical and social work, in Collection: Forms and methods of social work in various spheres of life Materials of the II International Scientific and Practical Conference, 2013, pp. 223-224.

[3] Yu.P. Lisitsyn, Public health and health care, GEOTAR-MED, Moscow, 2002, 520 p.

[4] A.V. Martynenko, Medical and social work: theory, technology, education, Nauka, Moscow, 1999, 240 p.

[5] E.Yu. Kostina, History of Social Work, Far Eastern Univer. Publ. House, Vladivostok, 2004, 110 p.
[6] Palliative care for adults and children: organization and vocational training, in: Collection of WHO and EAPC documents, R. Valent, Moscow, 2014.

[7] K. Froggatt, K. Heimerl, Palliative Care in LongTerm Care Settings for Older People: An International Perspective, Europ. J. of Palliative Care, 15(5) (2008) 244-247.

[8] K. Froggatt, E. Reitinger, Palliative Care in LongTerm Care Settings for Older People: introducing an EAPC Taskforce, Europ. J. of Palliative Care 18(1) (2011) 26-28.

[9] R. MacLeod, Challenges for education in palliative care, Progress in Palliative Care 12(3) (2004) 117-121.

[10] L. Radbruch, S. Payne and EAPC Board of Directors, White paper on standards and norms for hospice and palliative care in Europe: part 2, Europ. J. of Palliative Care 17(1) (2010) 22-23.

[11] G. Taranyuk, Health in self-assessments of the population, Sociology: theory, methods, marketing 2 (2012) 120-133.

[12] I. Vetlugin, Palliative care: state and problems, Medical newspaper, 4 May 2016, Retrieved from: http://www.mgzt.ru/content 